\title{
Expression of Toll-Like Receptor 2 (TLR2) and TLR4 in Response to Aspergillus Fumigatus in Murine Models of Allergic Airway Inflammation
}

\author{
Gabriel Moran ${ }^{1 *}$, Evelyn Arevalo', Miguel Barria ${ }^{2}$, Alexander Ortloff and Hugo Folch ${ }^{2}$ \\ ${ }^{1}$ Department of Pharmacology and Morphophysiology, Faculty of Veterinary Science, Universidad Austral de Chile, \\ Valdivia, Chile
}

${ }^{2}$ Department of Immunology, Faculty of Medicine, Universidad Austral de Chile, Valdivia, Chile

${ }^{3}$ College of Veterinary Medicine, Universidad Catolica de Temuco, Chile

*Corresponding author: Gabriel Morán, Department of Pharmacology and Morphophysiology, Faculty of Veterinary Science, Universidad Austral de Chile, Valdivia, Chile, Tel: +56-63-221936, Fax: +56-63-221444, E-mail: gmoran@uach.cl

\begin{abstract}
Toll-like receptors (TLRs) constitute a protein family of cellular receptors that mediate the recognition of microbial challenges and the subsequent inflammatory response. The role of these receptors in allergic diseases of airways remains unclear. The objective of this study was to evaluate TLR2 and TLR4 expression in the lung in a murine model of bronchial hypersensitivity to Aspergillus fumigatus. Different groups of 5-month-old mice (Balb/c) were housed in cages containing hay bedding that was contaminated with $A$. fumigatus and were kept in an isolation room for 16 days to allow for the induction of allergic airway inflammation. The mice were then exposed once again to Aspergillus spores for $0,2,6,12$ and 24 hours; the mice were then sacrificed to obtain bronchoalveolar lavage fluid (BALF) or lung tissues for histology analysis; TLR2 and TLR4 expression. An unexposed group was used as a control. The results indicated that in this allergic mouse model, during the first hours of exposure to $A$. fumigatus spores in mice previously sensitized to this fungus, there is a decrease in the expression of TLR2 and TLR4 receptors with a concomitant increase in neutrophils in the BALF and histological changes associated with bronchial hyper responsiveness. The difference between our results and those of other studies could be due to the timing, dose, site and intensity of exposure of allergen, environmental factors and host genetic predisposition. This may explain the disparate results of TLR receptor expression during the development of allergies and airway inflammation.
\end{abstract}

\section{Keywords}

TLR2, TLR4, Aspergillus fumigatus, Allergy, Airway inflammation

\section{Introduction}

Aspergillus fumigatus is a saprophyte fungus that survives and grows over a large variety of organic remains and whose most common ecological niche is on the ground. It is one of the most ubiquitous fungi due to the ease of dispersion of its conidia [1]. The small size of the conidia, from 2 to $3 \mu \mathrm{m}$, means that they can remain in suspension in the environment for a long period of time and can reach the human pulmonary alveoli because man is constantly exposed by inhaling them [2]. Aspergillus, a ubiquitous mold, affects the respiratory system in more ways than one. The clinical spectrum of Aspergillus-associated hypersensitivity respiratory disorders includes Aspergillus-induced asthma, allergic bronchopulmonary aspergillosis (ABPA), and allergic Aspergillus sinusitis, which are usually observed in atopic subjects [3]. A. fumigatus produces a significant number of allergenic molecules that react with IgE in asthmatic patients and in patients with ABPA [4].

Allergic airway inflammation is one characteristic feature of asthma, with additional pathology including a reversible airway obstruction; airway hyperresponsiveness (AHR), the infiltration of eosinophils and Thelper type 2 (Th2) cells into the airway submucosa, mucus hypersecretion and airway remodeling [5]. Allergic airway diseases are inflammatory disorders in which aberrant immune regulation occurs and susceptible individuals display allergen-specific responses. In these responses, inflammatory cells are recruited to the asthmatic airways or are activated in situ. These inflammatory cells include mast cells, macrophages, eosinophils, T lymphocytes, dendritic cells, basophils, neutrophils and platelets [6].

The innate immune system confers rapid recognition of a wide spectrum of pathogens using a limited repertoire of germlineencoded proteins, such as pattern recognition receptors (PRRs) [7]. Chemically diverse bacterial products, such as saccharides, proteins, lipopolysaccharides (LPSs), peptidoglycans, lipopeptides, lipids and nucleic acids, serve as agonists to these receptors. Toll-like receptors (TLRs) are essential PRRs and constitute a novel protein family of cellular receptors that mediate the recognition of microbial challenges and the subsequent inflammatory response in vertebrates [8]. Their ability to detect the specific pathogen-associated molecular patterns

\section{Clin Med International Library}

Citation: Moran G, Arevalo E, Barria M, Ortloff A, Folch H (2015) Expression of Toll-Like Receptor 2 (TLR2) and TLR4 in Response to Aspergillus Fumigatus in Murine Models of Allergic Airway Inflammation. Int J Immunol Immunother 2:015

Received: March 10, 2015: Accepted: November 23, 2015: Published: December 01, 2015 Copyright: (c) 2015 Moran G. This is an open-access article distributed under the terms of the Creative Commons Attribution License, which permits unrestricted use, distribution, and reproduction in any medium, provided the original author and source are credited. 
of Aspergillus conidia involves the expression of PRRs, and the main families of these receptors are the TLRs and the lectin receptors. TLR2 and TLR4 have been reported to mediate the recognition of various cell wall components of Aspergillus [9-12], and dectin-1, a C-type lectin receptor, is the major PRR involved in the recognition of $\beta$-glucans [13-15]. The involvement of TLRs in the pathogenesis of allergic diseases results from the biological function that they play in the activation and regulation of the immune response. However, the exact role of these receptors remains controversial. Whereas numerous epidemiological studies mainly indicate a protective effect against microbial exposure, experiments show that innate immune stimulation via TLRs may be involved in both the development of and protection against allergic diseases [16]. Overall, the role of TLRs in allergic inflammation of the airways is still not well understood.

The objective of the current study was to evaluate whether TLR2 and TLR4 levels increase in the lung tissue of a murine model of neutrophil airway inflammation. We want to show that within several hours, the components of $A$. fumigatus may induce the expression of TLR2 and TLR4, a factor in the initial bronchial allergic inflammation response

\section{Materials and Methods}

\section{Animals}

For all of the experiments in this study, we used 5-month-old, sexand age-matched $\mathrm{BALB} / \mathrm{c}$ mice. These animals were obtained from and maintained at the Animal Facility of the Universidad Austral de Chile. During the exposure of these animals to A. fumigatus, they were placed in an isolation room with appropriate ventilation and filtering systems. This study was approved by the Bioethics Committee for the Use of Animals in Biomedical Research of the Universidad Austral de Chile.

\section{Exposure of mice to A. fumigatus spores}

Different groups of 5-month-old mice (eight mice per group) were housed in cages containing hay bedding that was contaminated with A. fumigatus and were kept in an isolation room for 16 days to allow for the induction of allergic airway inflammation, as described in previously published procedures [17,18]. After 16 days of exposure to this mold, the mice were placed in a remission environment for 10 days with the purpose of having the animals in a basal inflammatory condition before starting the antigenic challenge. Subsequently, the mice were once again exposed to the Aspergillus spores. At $0,2,6$, 12 and 24 hours after this exposure, the mice were sacrificed with an overdose of a sodium barbital anesthetic (Serve, USA) to obtain the bronchoalveolar lavage fluid (BALF) or lung tissues for analysis, as described in previously published procedures $[17,18]$. An unexposed group was used as a control.

\section{Bronchoalveolar lavage fluid and lung histology}

Different groups of mice were used for the bronchoalveolar lavage fluid (BALF) and analysis of lung tissues to prevent any possible alteration of the histological appearance of the lungs due to the lavage. The animals were sacrificed using an overdose of a sodium barbital anesthetic (Serve, USA). For the BALF, the trachea was surgically exposed and cannulated with an intravenous catheter (22 Gx 1/in), and $300 \mu \mathrm{L}$ of saline solution was slowly administered into the trachea and immediately recovered. The obtained BALF was centrifuged at $690 \mathrm{x} g$. The cell pellet was used for cytological analyses. For histological sections, experimental lung tissues were fixed in $4 \%$ formaldehyde, embedded in Paraplast, cut into 5- $\mu \mathrm{m}$ sections, and stained with hematoxylin-eosin [17].

Determination of TLR2 and TLR4 expression levels in the lung through reverse transcription polymerase chain reaction ( $R T-P C R)$

Total RNA Kit (TRK) lysis buffer (Omega Bio-Tek Inc., USA) was prepared by adding $14 \mu \mathrm{l}$ of $\beta$-mercaptoethanol to every $700 \mu \mathrm{l}$ of lysis buffer. A total of $700 \mu \mathrm{l}$ of autoclaved TRK lysis buffer was added to homogenized pulmonary tissue in a sterile 2-ml Eppendorf tube. The solution was then added to a HiBind column (Omega Bio-Tek Inc., USA) in a collection tube and centrifuged at 9,000 $\mathrm{x} g$ for 60 seconds at $15^{\circ} \mathrm{C}$. The flow through was discarded. The column was placed in a new 2-ml collection tube, washed with $500 \mu \mathrm{l}$ of RNA wash buffer I (Omega Bio-Tek Inc., USA), and then centrifuged as described above, again discarding the flow through. Subsequently, the column was washed with $500 \mu \mathrm{l}$ of RNA wash buffer II (Omega Bio-Tek Inc., USA) that had been diluted with absolute ethanol and centrifuged at $9,000 \times \mathrm{g}$ for 60 seconds at $15^{\circ} \mathrm{C}$. A portion of the flow through was reused over the collection tube in the next step, while the excess flow through was discarded. The collection tube was back-washed with $350 \mu$ of wash buffer II in absolute ethanol and centrifuged as described above; the flow through was discarded. The collection tube was then centrifuged at $12,000 \mathrm{x} g$ in a column for 2 minutes at $15^{\circ} \mathrm{C}$ to completely dry the array. The RNA column was then inserted into a $15-\mathrm{ml}$ centrifuge tube, and the RNA was eluted in $100 \mu$ of deionized water that had been rendered RNase-free through treatment with $0.1 \%$ diethyl pyrocarbonate (DEPC, Sigma); the water was added directly to the column matrix, and the column was then centrifuged for $1 \mathrm{~min}$ at 9,000 $\mathrm{x}$ g. Once the RNA was isolated, an ImProm II Kit (Promega Co., USA) was used in accordance with the manufacturer's instructions to generate cDNA. For each PCR amplification, $1 \mu \mathrm{l}$ of the cDNA that was synthesized in the previous step was used as a template; this cDNA was combined with $24 \mu$ l of a mix containing all of the other necessary PCR reagents in a $0.2-\mathrm{ml}$ tube. The final concentration of the reaction components was as follows: $1 \mathrm{X}$ Taq polymerase buffer, $1 \mathrm{mM} \mathrm{MgCl}, 100 \mu \mathrm{M}$ of each dNTP, $0.4 \mu \mathrm{M}$ of both the sense ( $5^{\prime}$ TTT GCT CCT GCG AAC TCC TA $\left.3^{\prime}\right)$ and antisense $\left(5^{\prime}\right.$ GCT TTC TTG GGC TTC CTC TT 3') oligonucleotides for TLR2 or sense ( $5^{\prime}$-GCT GGA TTT ATC CAG GTG TG-3') and antisense ( $5^{\prime}$ TCT CCA CAG CCA CCA GAT TCT-3') oligonucleotides for TLR4; and $1 \mathrm{U}$ of Taq DNA polymerase (Go Taq, Promega Co., USA) in a final volume of $25 \mu \mathrm{L}$. The amplifications were performed in a PCR Sprint Thermal Cycler (Thermo Scientific Corporation). The PCR protocol utilized an initial denaturation at $94^{\circ} \mathrm{C}$ for $3 \mathrm{~min}$, which was followed by a series of 40 cycles $\left(95^{\circ} \mathrm{C}\right.$ for $45 \mathrm{sec}, 55^{\circ} \mathrm{C}$ for $45 \mathrm{sec}$, and $72^{\circ} \mathrm{C}$ for $45 \mathrm{sec}$ ) and a final 5-min elongation step at $72^{\circ} \mathrm{C}$. In addition, housekeeping genes (GAPDH; sense: 5' CTC ATG ACC ACA GTC CAT GC 3', antisense: 5' GCC TGC TTC ACC ACC TTC TT 3') were used as loading controls for the RT-PCR amplifications. The products that were obtained for TLR2 (291 bp), TLR4 (157 bp) and GAPDH (390 bp) were resolved on a $2 \%$ agarose gel using electrophoresis in 1X TAE (10 mM Tris- $\mathrm{HCl}, 0.1 \%$ acetic acid, 1 mM EDTA, pH 8.0). The intensity of the PCR product band that was obtained for each gene was quantified using the Image J software package; we then calculated the TLR2 and TLR4/GAPDH ratio.

\section{Data analysis}

The results of the percentage of neutrophils in the BALF and values of the TLR2 and TLR4/GAPDH ratio were assessed by ANOVA. When significant, the means were compared using a Tukey's Multiple Comparison Test. The results are reported as the mean $\pm \mathrm{SD}$. A value of $\mathrm{P}<0.05$ was considered significant.

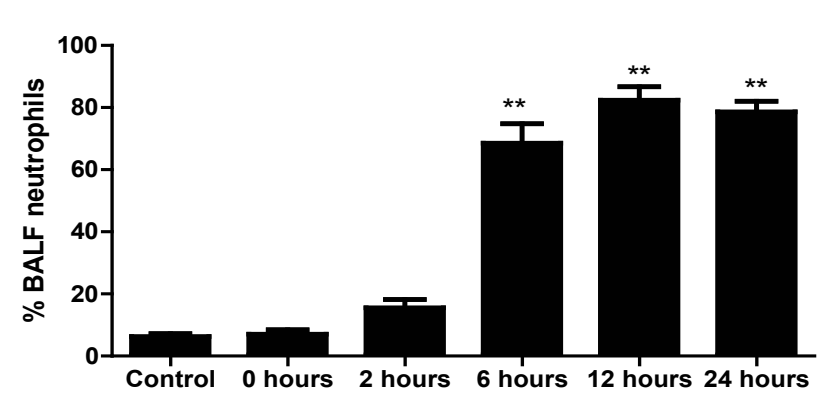

Figure 1: Percentage of neutrophils in the bronchoalveolar lavage fluid of mice at $0,2,6,12$ and 24 hours after exposure to $A$. fumigatus; and the control group (** indicate that $p<0.01$, respectively, compared among the groups of mice). 

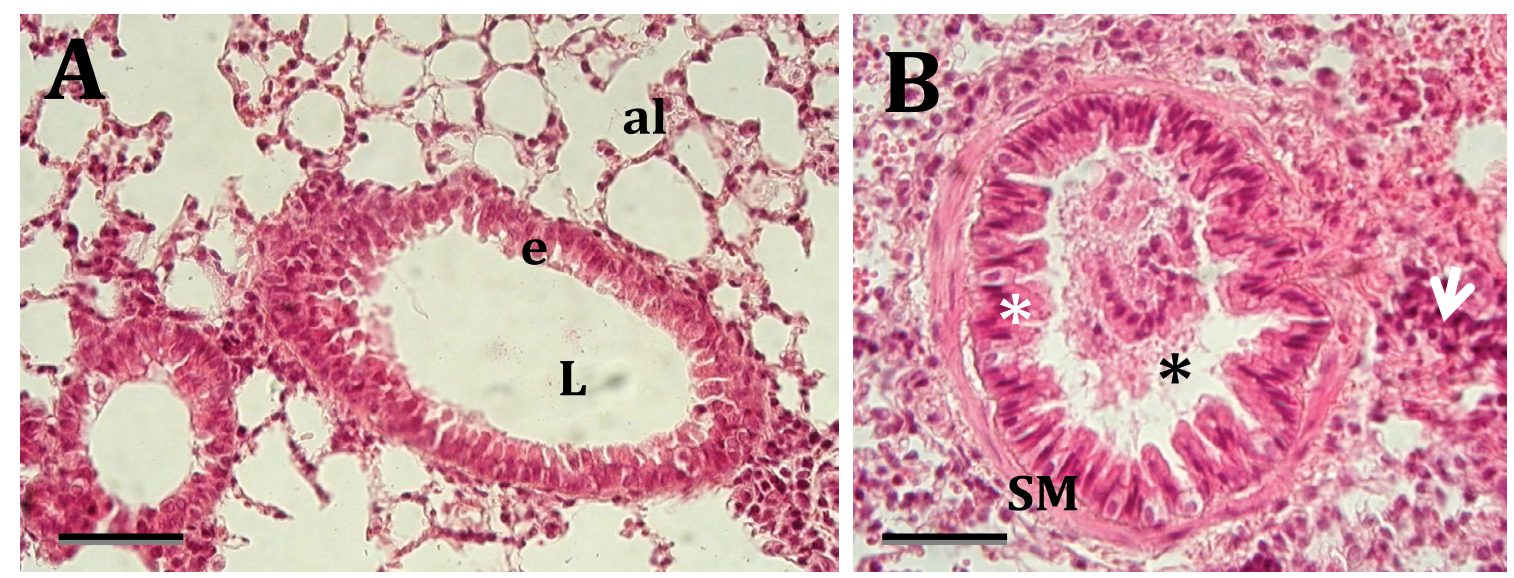

Figure 2: A) Representative histological slide of the lung of a mouse exposed to Aspergillus fumigatus for 0-6 hours. The bronchioles do not have infiltration of inflammatory cells in the epithelium (e) and lumen (L). The alveoli (al) are normal.

B) Representative histological slide of the lung of a mouse that was exposed to Aspergillus fumigatus for 12-24 hours. It is possible to see peribronchiolar and alveolar infiltration of inflammatory cells (white arrows). The bronchiolar lumen was stenosed by cell debris (black asterisk), and extensive folding of the airway epithelium was observed. Extensive folding is a sign of smooth muscle (SM) contraction (white asterisk). Staining with hematoxylin and eosin (H-E). Scale bar $=$ $35 \mu \mathrm{m}$.

\section{Results}

\section{Analysis of the cellular composition of the BALF}

The differential neutrophil counts in the BALF from A. fumigatusexposed mice are shown in figure 1. The cells recovered from the BALF of the exposed mice exhibited a significant increase in the proportion of polymorphonuclear neutrophils after 6 hours. There were significantly greater proportions of neutrophils in mice that were exposed from 6-24 hours compared to those who were exposed to A. fumigatus for 0-2 hours.

\section{Histopathological evaluation}

Figures $2 \mathrm{~A}$ and Figure $2 \mathrm{~B}$ demonstrates the histopathological changes that occurred in the airways of A. fumigatus-exposed mice. Clear changes in the airway histopathology were only observed in mice exposed to A. fumigatus between 6-24 hours. The luminal surface epithelium in the bronchiolar airways of the unaffected mice was composed of thin cuboidal epithelial cells. These cells were mostly non-ciliated Clara cells and ciliated cells either with or without a few intervening mucus cells (Figure 2A). We observed pathological symptoms in the lungs of animals exposed to A. fumigatus for 6-12 hours. The bronchiolitis observed in animals exposed to A. fumigatus was characterized by significant peribronchiolar and perivascular mononuclear and neutrophilic infiltration, the accumulation of intraluminal bronchiolar mucus and serofibrinous exudates. Moreover, there was extensive folding of the airway epithelia, a sign of airway smooth muscle contraction and smooth muscle hypertrophy. This inflammatory response was observed predominantly in the peribronchiolar interstitial tissues and often extended into the lamina propria and luminal surface epithelium of the affected airways. We also observed infiltration of the inflammatory cells into the alveolar space (Figure 2B)

\section{Levels of TLR2 mRNA and TLR4 mRNA in the lung}

The results of TLR mRNA expression in the lungs of susceptible mice exposed to A. fumigatus contradict the results from the BALF and histology (Figure 3). The results show that after 2 hours of exposure to the antigen, the expression of both receptors fall significantly compared with time 0 . In the case of TLR2 mRNA, low levels of expression occurred within 2 hours of exposure and remained low for 24 hours. Additionally, TLR4 mRNA had a significant decrease in expression at 2 hours compared to time 0 , but there was a much more significant decrease between 6-24 hours post-exposure to A. fumigatus.

\section{Discussion}

In this study, we evaluated the effect of $A$. fumigatus spores on the
A

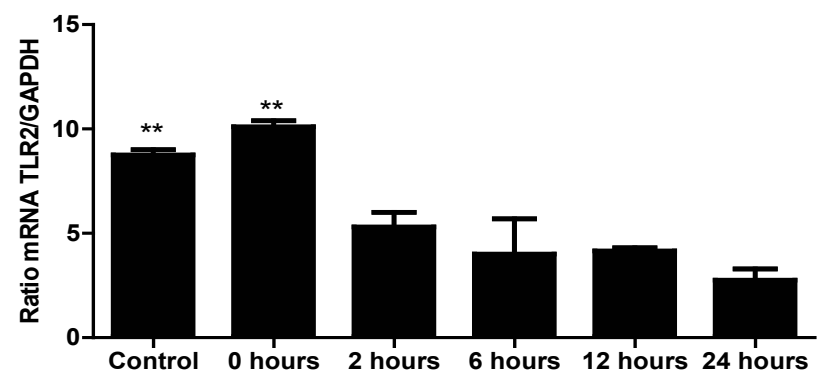

B

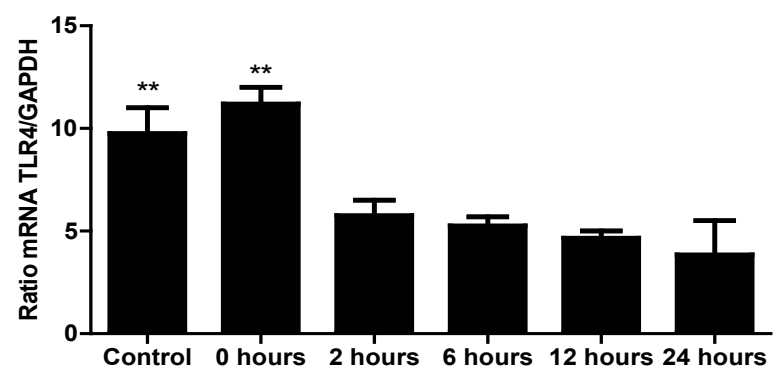

Figure 3: Measurement of TLR2 and TLR4 mRNA expression by RT-PCR in mice $0,2,6,12$ and 24 hours after exposure to $A$. fumigatus; and control group

A) The expression of TLR2 mRNA in the lung.

B) The expression of TLR4 mRNA in the lungs. TLR2 and TLR4 mRNA expression levels are presented in terms of the TLR2 or TLR4/GAPDH ratio for each experimental group of mice. The bars represent the average result from triplicate experiments for lung samples for each sampled. $\left({ }^{* *} p<0.01\right.$, compared among the groups of mice)

expression of TLR2 and TLR4 at the bronchial level to understand the role of these receptors in the first hours of exposure in mice previously sensitized by this fungus. A. fumigatus spores can quickly stimulate immune responses and are responsible for a wide spectrum of respiratory ailments, ranging from pulmonary colonization to more invasive diseases. Aspergillus sp. is associated with hypersensitivity in respiratory disorders, including asthma, allergic bronchopulmonary aspergillosis, allergic sinusitis and hypersensitivity pneumonitis [19]. In addition, in patients with allergic asthma, inhalant allergens play a key role in bringing about inflammation in the airways, and fungi are 
increasingly being recognized as important inhalant allergens [20]. A. fumigatus is linked to asthma in more ways than one. In asthmatic subjects, the fungal spores are trapped in the thick and viscid secretions that are usually present in the airways. This generally develops in atopic subjects and is sustained by continuous inhalation of $A$. fumigatus antigens, triggering even more severe asthma. Aspergillusinduced asthma has yet to receive the recognition that it deserves [19]. Moreover, neutrophilic asthma is an important subgroup of the disease which includes patients with severe phenotypes. In the current study, the mice were exposed to fungus spores to generate a bronchial hypersensitivity response characterized by massive infiltration of the airways by inflammatory cells, as previously published [17,18].

The function of TLRs in allergic airway inflammation is in part mediated by the activation of cells of the innate immune system. It has been observed that proteins secreted by the fungus and present in the culture supernatant can activate dendritic and neutrophil cells, and this activation is mediated by TLR2 and TLR4 [21]. Dendritic, mast cells and neutrophils are the major players in allergic asthma. Mast cell activation and the subsequent secretion of proinflammatory cytokines and chemokines are directly induced by TLR ligands without the induction of degranulation and arachidonic acid metabolism [22-27]. However, in this study, under our experimental conditions, we observed a decrease in the expression of TLR2 and TLR4 in sensitized mice that had further contact with the fungal spores for 2-24 hours with a bronchial hypersensitivity response. Some authors suggest that the cellular expression of TLRs could be influenced by microenvironmental conditions, which is a topic that is starting to get more attention [28]. These same authors have shown that the surface expression of TLR4 is down regulated upon short-term exposure to cigarette smoke, which can be explained by the internalization of the receptor. Other authors have shown that the down regulation of the TLR2-mediated pathway involves the internalization of the receptor together with Aspergillus conidia into the phagosome, resulting in the decreased expression of TLR2 on the cell membrane [29]. Furthermore, TLR expression may be different in activated vs. non-activated inflammatory cells. TLR4 expression on monocytes, lymphocytes and dendritic cells in patients with asthma has been shown to be significantly lower compared with control subjects [30]. Our results and those of other authors may suggest that the internalization of TLRs is not indicative of a decrease in the effect of inflammation on the airways. Our results demonstrate that in animals sensitized with A. fumigatus, and reexposure to antigen, there was no change in TLR expression with neutrophilic cell infiltration in the BALF, and histological findings were consistent with a bronchial allergic response. However, in other studies, the increased expression of TLR2, 3 and 4 in fatal asthma may contribute to the acute inflammation leading to asthma-related deaths [31]. Furthermore, BALF cells obtained from patients with chronic obstructive pulmonary disease (COPD) had increased TLR4 expression, which could promote airway neutrophilic inflammation [32].

However, the role of TLRs in airway allergy is not well understood because several studies show that these receptors could have a role in modulating the immune response, decreasing the clinical symptoms of asthma. Redirecting an allergic Th2 response by triggering a Th1 response via TLR activation has been postulated as an approach to treat patients with asthma [30]. Hollingsworth et al. [33] shows that the attenuation of eosinophilic inflammation in C57BL/6 mice was abolished when these mice were challenged with OVA supplemented with additional LPS. These findings show that low doses of endotoxin can have regulatory effects on allergic inflammation, particularly in the setting of ongoing allergen exposure. Furthermore, experiments in mice treated with this TLR4 antagonist showed reduced granulocyte and lymphocyte cells, reduced levels of the Th2 cytokines IL- 5 and IL-13 in the BALF, decreased goblet cell hyperplasia and lower airway hyperresponsiveness [34]. Apparently, the timing, dose, site and intensity of exposure to environmental factors and host genetic predisposition are clearly crucial to understanding the interaction between TLRs and the development of allergy [35-37]. This may explain the disparate results of TLR receptor expression during the development of allergies and airway inflammation.

In conclusion, this allergic mouse model shows that in mice previously sensitized to A. fumigatus spores, the first hours of re-exposure to this fungus are characterized by a decrease in the expression of TLR2 and TLR4 receptors with a concomitant increase in the neutrophils in the BALF and histological changes associated with bronchial hyperresponsiveness. The difference between our results and those of other studies could be due to the timing, dose, site and intensity of exposure of allergen, environmental factors and host genetic predisposition. However, further studies are required to better understand the role of TLRs, in particular TLR2 and TLR4, during the initial response to allergen exposure and to further understand the interaction between TLRs and allergy development.

\section{Acknowledgements}

This work was supported by DID- UACH-S-2009-22 of Universidad Austral de Chile and Fondecyt 1130355

\section{Conflict of Interest Statement}

None of the authors have any financial or personal relationships that could inappropriately influence or bias the content of the paper.

\section{References}

1. Latgé JP (1999) Aspergillus fumigatus and aspergillosis. Clin Microbiol Rev 12: $310-350$.

2. Abarca ML (2000) Taxonomy and identification of the species involved in nosocomial aspergillosis. Rev Iberoam Micol 17: S79-84.

3. Banerjee B, Kurup VP, Greenberger PA, Johnson BD, Fink JN (2001) Cloning and expression of Aspergillus fumigatus allergen Asp $f 16$ mediating both humoral and cell-mediated immunity in allergic bronchopulmonary aspergillosis (ABPA). Clin Exp Allergy 31: 761-770.

4. Banerjee B, Kurup VP (2003) Molecular biology of Aspergillus allergens Front Biosci 8: s128-139.

5. Agrawal DK, Shao Z (2010) Pathogenesis of allergic airway inflammation Curr Allergy Asthma Rep 10: 39-48

6. Barnes PJ, Chung KF, Page CP (1998) Inflammatory mediators of asthma: an update. Pharmacol Rev 50: 515-596.

7. Kopp E, Medzhitov R (2003) Recognition of microbial infection by Toll-like receptors. Curr Opin Immunol 15: 396-401.

8. Takeda K, Kaisho T, Akira S (2003) Toll-like receptors. Annu Rev Immunol 21: 335-376.

9. Bellocchio S, Montagnoli C, Bozza S, Gaziano R, Rossi G, et al. (2004) The contribution of the Toll-like/IL-1 receptor superfamily to innate and adaptive immunity to fungal pathogens in vivo. J Immunol 172: 3059-3069.

10. Matsushima H, Yamada N, Matsue H, Shimada S (2004) TLR3-, TLR7-, and TLR9-mediated production of proinflammatory cytokines and chemokines from murine connective tissue type skin-derived mast cells but not from bone marrow derived mast cells. J Immunol 173: 531-541.

11. Meier A, Kirschning CJ, Nikolaus T, Wagner H, Heesemann J, et al. (2003) Toll-like receptor (TLR)2 and TLR4 are essential for Aspergillus-induced activation of murine macrophages. Cell Microbiol 5: 561-570.

12. Wang JE, Warris A, Ellingsen EA, Jørgensen PF, Flo TH, et al. (2001) Involvement of CD14 and toll-like receptors in activation of human monocytes by Aspergillus fumigatus hyphae. Infect Immun 69: 2402-2406.

13. Netea MG, Brown GD, Kullberg BJ, Gow NA (2008) An integrated model of the recognition of Candida albicans by the innate immune system. Nat Rev Microbiol 6: 67-78.

14. Romani $L$ (2004) Immunity to fungal infections. Nat Rev Immunol 4: 1-23.

15. Steele C, Rapaka RR, Metz A, Pop SM, Williams DL, et al. (2005) The betaglucan receptor dectin-1 recognizes specific morphologies of Aspergillus fumigatus. PLoS Pathog 1: e42.

16. Dębińska A, Boznański A (2014) The role of Toll-like receptors in the pathogenesis of allergic diseases - where is the truth. Postepy Hig Med Dosw (Online) 68: 230-237.

17. Moran G, Ojeda G, Diedrichs K, Ortloff A, Barria M, et al. (2011) Inhalation of Aspergillus fumigatus spores induces airway inflammation in mice in a similar manner as observed in Recurrent Airway Obstruction in horses. Arch Med Vet 43: 163-171.

18. Moran G, Carcamo C, Concha M, Folch H (2015) Expression of the protein serum amyloid A (SAA) in response to Aspergillus fumigatus in murine models of allergic airway inflammation. Rev Iberoam Micol 32: 25-29. 
19. Shah A (2008) Aspergillus-associated hypersensitivity respiratory disorders Indian J Chest Dis Allied Sci 50: 117-128.

20. Kurup VP, Shen HD, Banerjee B (2000) Respiratory fungal allergy. Microbes Infect 2: 1101-1110.

21. Braedel S, Radsak M, Einsele H, Latgé JP, Michan A, et al. (2004) Aspergillus fumigatus antigens activate innate immune cells via toll-like receptors 2 and 4. Br J Haematol 125: 392-399.

22. McCurdy JD, Lin TJ, Marshall JS (2001) Toll-like receptor 4-mediated activation of murine mast cells. J Leukoc Biol 70: 977-984.

23. Hines C (2002) The diverse effects of mast cell mediators. Clin Rev Allergy Immunol 22: 149-160.

24. Kulka M, Alexopoulou L, Flavell RA, Metcalfe DD (2004) Activation of mas cells by double-stranded RNA: evidence for activation through Toll-like receptor 3. J Allergy Clin Immunol 114: 174-182.

25. Mambula SS, Sau K, Henneke P, Golenbock DT, Levitz SM (2002) Toll-like receptor (TLR) signaling in response to Aspergillus fumigatus. J Biol Chem 277: 39320-39326.

26. Kambayashi T, Larosa DF, Silverman MA, Koretzky GA (2009) Cooperation of adapter molecules in proximal signaling cascades during allergic inflammation. Immunol Rev 232: 99-114.

27. Mrabet-Dahbi S, Metz M, Dudeck A, Zuberbier T, Maurer M (2009) Murine mast cells secrete a unique profile of cytokines and prostaglandins in response to distinct TLR2 ligands. Exp Dermatol 18: 437-444.

28. Sarir H, Mortaz E, Karimi K, Kraneveld AD, Rahman I, et al. (2009) Cigarette smoke regulates the expression of TLR4 and IL- 8 production by human macrophages. J Inflamm (Lond) 6: 12.
29. Chai LY, Kullberg BJ, Vonk AG, Warris A, Cambi A, et al. (2009) Modulation of Toll-like receptor 2 (TLR2) and TLR4 responses by Aspergillus fumigatus. Infect Immun 77: 2184-2192.

30. Bezemer GF, Sagar S, van Bergenhenegouwen J, Georgiou NA, Garssen J, et al. (2012) Dual role of Toll-like receptors in asthma and chronic obstructive pulmonary disease. Pharmacol Rev 64: 337-358.

31. Ferreira DS, Annoni R, Silva LF, Buttignol M, Santos AB, et al. (2012) Tolllike receptors 2, 3 and 4 and thymic stromal lymphopoietin expression in fatal asthma. Clin Exp Allergy 42: 1459-1471.

32. Pace E, Giarratano A, Ferraro M, Bruno A, Siena L, et al. (2011) TLR4 upregulation underpins airway neutrophilia in smokers with chronic obstructive pulmonary disease and acute respiratory failure. Hum Immunol 72: 54-62.

33. Hollingsworth JW, Whitehead GS, Lin KL, Nakano H, Gunn MD, et al. (2006) TLR4 signaling attenuates ongoing allergic inflammation. J Immunol 176: 5856-5862.

34. Hammad H, Chieppa M, Perros F, Willart MA, Germain RN, et al. (2009) House dust mite allergen induces asthma via Toll-like receptor 4 triggering of airway structural cells. Nat Med 15: 410-416.

35. Fonseca DE, Kline JN (2009) Use of CpG oligonucleotides in treatment of asthma and allergic disease. Adv Drug Deliv Rev 61: 256-262.

36. Gomariz RP, Gutiérrez-Cañas I, Arranz A, Carrión M, Juarranz Y, et al. (2010) Peptides targeting Toll-like receptor signalling pathways for novel immune therapeutics. Curr Pharm Des 16: 1063-1080.

37. Kuznik A, Panter G, Jerala R (2010) Recognition of nucleic acids by Toll-like receptors and development of immunomodulatory drugs. Curr Med Chem 17 : 1899-1914. 